De Twitter a Instagram: ¿̇Qué red social eligen las revistas de moda y belleza? | 179

ARTÍCULOS DE INVESTIGACIÓN

\title{
De Twitter a Instagram: ¿Qué red social eligen las revistas de moda y belleza?
}

\section{From Twitter to Instagram: What social network do fashion and beauty magazines choose?}

\section{Do Twitter ao Instagram: Qual rede social as revistas de moda e beleza escolhem?}

\author{
Dra. Ruth Gómez de Travesedo Rojas \\ Profesora en el departamento de Comunicación Audiovisual y Publicidad \\ Facultad de Ciencias de la Comunicación \\ (Universidad de Málaga) \\ http://orcid.org/0000-0003-4452-5928 \\ España \\ Dra. Marta Gil Ramírez \\ Profesora en el departamento de Comunicación Audiovisual y Publicidad \\ Facultad de Ciencias de la Comunicación \\ (Universidad de Málaga) \\ http://orcid.org/0000-0002-0577-5628 \\ España
}

Fecha de recepción: 16 de mayo de 2019

Fecha de revisión: 4 de octubre de 2019

Fecha de aceptación: 5 de diciembre de 2019

Fecha de publicación: 1 de enero de 2020

Para citar este artículo: Gómez de Travesedo Rojas, R. y Gil Ramírez, M. (2020). De Twitter a Instagram: ¿Qué red social eligen las revistas de moda y belleza?, Icono 14, 18 (1), 179-204. doi: 10.7195/ri14.v18i1.1395 


\section{Resumen}

En los últimos años las revistas de moda y belleza, aunque no han abandonado su edición impresa, no han podido quedarse al margen de la realidad actual: una sociedad altamente digitalizada, que acude con mucha frecuencia a Internet y en la que las redes sociales ganan cada día mayor protagonismo, sobre todo entre el público femenino más joven. Por este motivo, las propias revistas, ya en los años 90 del siglo pasado, lanzaron sus portales web y cuentan también con presencia en redes sociales con alcance global. Resulta lógico pensar que estas cabeceras presten más atención a redes sociales que dan mayor protagonismo a la imagen, como Instagram, Pinterest o YouTube, ya que su temática se centra en contenidos con un alto componente visual. De este modo, se analizarán, mediante el análisis de contenido, las redes sociales más empleadas, recogiendo información referida al número y tipo de redes utilizadas, nivel de visibilidad y exposición, así como nivel de interacción e involucración de sus seguidores. Los resultados muestran que, aunque la interacción e involucración es mayor en redes visuales, las revistas aún no son conscientes de esta circunstancia y dedican sus mayores esfuerzos a redes textuales.

Palabras clave: Revistas femeninas; Moda; Belleza; Redes sociales; Internet; Género

\section{Abstract}

In recent years fashion and beauty magazines, although they have not abandoned their printed edition, have not been able to stay out of the current reality: a highly digitized society, which goes very often to the Internet and in which social networks win more prominence every day, especially among the younger female audience. For this reason, the magazines themselves, already in the 90s of the last century, launched their web portals and also have a presence on social networks with global reach. It is logical to think that these magazines pay more attention to social networks that give greater prominence to the image, such as Instagram, Pinterest or YouTube, because its theme focuses on content with a high visual component. In this way, the most used social networks will be analyzed through analysis of content, collecting information about the number and type of networks used, level of visibility and exposure, as well as the level of interaction and involvement of its followers. 
The results show that, although the interaction and involvement is greater in visual networks, the magazines are not yet aware of this and dedicate their greatest efforts to textual networks.

Key Words: Women's magazines; Fashion; Beauty; Social networks; Internet; Gender

\section{Resumo}

Nos últimos anos, revistas de moda e beleza, embora não tenham deixado a sua edição impressa, não conseguiram se manter fora da realidade atual: uma sociedade altamente digitalizada, que vai muito frequentemente à Internet e em que as redes sociais ganham mais destaque a cada dia, especialmente entre o público feminino mais jovem. Por esta razão, as própias revistas, já nos años 90 do século passado, lançaram suas páginas da web e também têm presença em redes sociais com alcance global. É lógico pensar que esses publicações prestem mais atenção às redes sociais que dão maior importância à imagem, como Instagram, Pinterest ou YouTube, já que seu tema se concentra no conteúdo com alto componente visual. Através da análise de conteúdo, serão analisadas as redes sociais mais utilizadas, número e tipo de redes utilizadas, nível de visibilidade e exposição, assim como nivel de interação e envolvimento de seus seguidores. Os resultados mostram que, embora a interação e o envolvimento sejam maiores nas redes visuais, as revistas dedicam seus maiores esforços às redes textuais.

Palavras chave: Revistas femininas; Moda; Beleza; Redes sociais; Internet; Gênero

\section{Introducción}

Las revistas de moda y belleza surgen en los años 60 del siglo pasado, pero hay que esperar hasta los 80 , coincidiendo con la apertura de nuestro país al exterior, para poder hablar de auge de este tipo de prensa. Es en ese momento cuando los grandes títulos internacionales -Elle, Vogue o Cosmopolitan- aterrizan en el mercado español, arrollando con revistas nacionales que no logran ganar la batalla a las grandes editoras internacionales ${ }^{1}$ (Ganzabal, 2006). 


\section{ARTÍCULOS DE INVESTIGACIÓN}

Desde entonces, el mercado de las revistas de moda y belleza ha sufrido distintas remodelaciones, como la adaptación al formato bolsillo, que llega a la prensa femenina juvenil de la mano de Ragazza, en 1999, y posteriormente con Cosmopolitan en febrero de 2002; aunque es el lanzamiento en nuestro país de Glamour, en formato mini o pocket, el verdadero revulsivo para que la mayor parte de estas cabeceras decidan apostar por este formato (Ganzabal, 2008).

Posteriormente la crisis económica mundial, que afecta a nuestro país a principios de 2008, posibilita la aparición de revistas low cost con títulos como Cuore Stilo, iHola! Fashion, Grazia y Divinity, que imitan a las revistas femeninas de alta gama, aunque con contenidos de moda y belleza más asequibles.

Tampoco podemos perder de vista la que ha sido la gran crisis de los medios de comunicación, especialmente de los impresos: la crisis digital. La aparición de Internet va a suponer un cambio en la forma de consumir medios; pero también en los modos y estilos de vida. De hecho, no podemos pensar en nuestra sociedad actual sin pensar en Internet. "Internet es el tejido de nuestras vidas en este momento. No es futuro, es presente. Es un medio para todo, que interactúa con el conjunto de la sociedad" (Castells, 2001, p. 1).

Internet se ha configurado como un nuevo medio de comunicación al que el resto de los medios tradicionales han tenido que acomodar su estrategia (Canga, 2001). Nos ofrece otra forma de consumir, con una renovación de información constante, con contenidos gratuitos, instantáneos y actualizados; algo con lo que el formato papel no puede competir (Font, 2015).

De esta manera, la crisis digital va a suponer una nueva reestructuración del panorama mediático y una redistribución de la cuota de mercado. Los anunciantes, aunque en principio se muestran reticentes a invertir en soportes online, pronto advierten las ventajas de este nuevo medio, especialmente por su gran audiencia, que no deja de crecer, con cifras que a nivel mundial alcanzan los 4.388 millones de usuarios en Internet, según el Informe Digital 2019. “El número de usuarios únicos en internet crece continuamente, y a nivel mundial no solo en España" (Ayestarán, 2011, p. 141). 
De Twitter a Instagram: ¿Qué red social eligen las revistas de moda y belleza? | 183

ARTíCULOS DE INVESTIGACIÓN

Albertos (1997) auguraba en 1997 el final de los diarios en papel para el año 2020, algo que no está sucediendo. Sin embargo y aunque, de momento, los medios digitales conviven con los tradicionales, no podemos obviar el auge de los primeros, por lo que la mayoría de los diarios y revistas de todo el mundo tienen presencia también en la Red.

\subsection{La adaptación a Internet de las revistas de moda y belleza: de la mujer tradicional a la mujer digital}

Las revistas de moda y belleza se encuentran actualmente dentro de un contexto tecnológico y comunicativo que poco tiene que ver con el de años atrás. Casi nada queda ya del mercado mediático en el que unas cabeceras impresas competían con otras; ya que el desarrollo y la democratización de Internet han diversificado los modos de comunicación y han eliminado fronteras, favoreciendo la creación de plataformas y sitios webs. Ahora las revistas impresas compiten también con blogs de moda y belleza y con revistas femeninas digitales, dos productos que ofrecen en parte los mismos contenidos que las tradicionales cabeceras dirigidas a la mujer.

Sin embargo, y a pesar de que la crisis digital ha afectado a la audiencia e inversión publicitaria de todos los medios tradicionales, la prensa femenina de alta gama en soporte papel aún sigue registrando importantes cifras de audiencia ${ }^{2}$, por lo que no podemos decir que se trate un producto agotado.

A pesar de ello, las editoras se dan cuenta de la importancia de estar en Internet por tres motivos: luchar por no perder y mantener su cuota en un mercado tan competitivo como es el de la prensa femenina; acceder a nuevas lectoras más jóvenes, acostumbradas a otro tipo de consumo; y conservar a los anunciantes, que exigen presencia en Internet (Ganzabal, 2007a).

De hecho, los estudios demuestran la preferencia de los jóvenes a la hora de informarse por los medios online frente a los tradicionales. También lo ratifica Ganzabal (2007a) para quien es un hecho que los menores de 30 años están abandonando la lectura de medios impresos a favor de los medios digitales y de contenidos multimedia, y que esta circunstancia se deja notar, no ya solo en los diarios, sino también en 


\section{ARTÍCULOS DE INVESTIGACIÓN}

un producto más especializado como son las revistas. “Los jóvenes conviven con las pantallas de un modo espontáneo y natural. Han nacido y crecido en ese entorno, (...), han aprendido antes a manejar el interface tecnológico que a leer y escribir" (Gabelas y Marta, 2011, p. 11). Algo en lo que también coincide Ayestarán (2001):

Los menores de 30 años abandonan los medios impresos deslumbrados por las posibilidades de lo multimedia y la presencia en la red de sus revistas. Este segmento de audiencia comienza a ser más que imprescindible tanto para abrirse a este nuevo mercado, como para mantener su posición en él. Otro de los caminos de este tipo de publicaciones para no perder cuota en mercado y acceder a nuevos lectores, es la introducción y generalización de sus contenidos en on line. Así los grandes grupos editoriales, han ido incluyendo los sitios webs de estas revistas. Tan lógico es su uso, que actualmente, resulta impensable que estas publicaciones no tengan su correspondiente website. No hace falta pagar por el precio de las cabeceras de $\mathrm{RFAG}^{3}$ en internet, cualquiera que esté conectado puede tener acceso a ellas. (pp. 141-142)

Según Ganzabal (2007a, p. 69) "si hay un sector apto especialmente para las nuevas tendencias ese es el público femenino precisamente por su apego a las nuevas modas". Algo, que han sabido captar rápidamente las revistas de moda y belleza, que no han permanecido ajenas a esta circunstancia y se han adaptado también a la revolución digital.

Aunque sin abandonar su tradicional soporte papel, han creado ediciones digitales de sus cabeceras, conscientes de que sus lectoras más jóvenes no consumen revistas compradas en los quioscos sino a través de Internet. Se trata de nuevas generaciones nacidas con la cultura digital y es a través de esta como deben y pueden llegar a ellas. De hecho, las constantes remodelaciones y adaptaciones que a lo largo de su historia ha sufrido la prensa femenina son "una forma de actualización constante y de evitar, por tanto, la pérdida sucesiva de este nicho de mercado formado por público más joven" (Ganzabal, 2007a, p. 69). También Ayestarán (2011) señala que dichas publicaciones tienen un largo recorrido hacia el futuro, posicionándose y adaptándose a su nuevo entorno. De modo, que la presencia digital de este tipo de cabeceras es imprescindible. 
En este contexto, la prensa femenina se adapta a Internet con gran rapidez, casi a la misma vez que los diarios nacionales de información general. Elle y Cosmopolitan fueron las primeras en contar con su versión web a mediados de los 90 , cuando Internet era aún un fenómeno incipiente. En 1996, cuando apenas un 1\% de la población usaba Internet, Elle tenía ya su propio portal web y lo mismo Cosmopolitan un año más tarde.

Sin embargo, el auge digital de las revistas de moda y belleza se produce en el periodo marcado entre los años 2000 y 2003, cuando el mercado de consumo digital está más estabilizado. Es entonces cuando surgen las páginas web de Telva (2000), Vogue (2001), Glamour y Marie Claire (2002). El resto de las revistas que salen posteriormente al mercado en formato impreso lo hacen de forma simultánea con su versión en la Red (Ganzabal, 2007a; Armentia, Ganzabal y Marín, 2011).

En la actualidad todas las revistas de moda y belleza que se imprimen en soporte papel cuentan con página web propia (Tabla 1), por lo que este tipo de cabeceras se encuentran plenamente incorporadas al mercado digital.

La mayoría de las páginas tienen la terminación ".es", como señala Ganzabal (2007a) con el objeto de diferenciar la edición española de la publicación de la de otros países, salvo aquellas cabeceras que solo se editan en nuestro país.

Con respecto al tipo de contenidos ofrecidos por estas versiones digitales, las diferencias no son significativas. Para Armentia et al. (2011) estas versiones digitales de las revistas repiten el mismo discurso que sus homónimas ediciones impresas, actuando como un elemento de promoción de estas.

\begin{tabular}{|l|l|c|}
\hline \multicolumn{1}{|c|}{ Cabecera } & \multicolumn{1}{|c|}{ Página web } & Año \\
\hline Cosmopolitan & http://www.cosmopolitan.com/es/ & 1997 \\
\hline Cuore Stilo & http://www.stilo.es & 2011 \\
\hline Divinity & http://www.divinity.es/ & 2014 \\
\hline Elle & http://www.elle.com/es & 1996 \\
\hline
\end{tabular}


186 | Dra. Ruth Gómez de Travesedo Rojas y Dra. Marta Gil Ramírez

ARTÍCULOS DE INVESTIGACIÓN

\begin{tabular}{|l|l|c|}
\hline \multicolumn{1}{|c|}{ Cabecera } & \multicolumn{1}{|c|}{ Página web } & Año \\
\hline Glamour & http://www.glamour.es/ & 2002 \\
\hline Harper's Bazaar & http://www.harpersbazaar.com/es & 2010 \\
\hline iHola! Fashion & http://fashion.hola.com/ & 2012 \\
\hline In Style & http://www.instyle.es/ & 2004 \\
\hline Marie Claire & http://www.marie-claire.es/ & 2002 \\
\hline Telva & http://www.telva.com/ & 2000 \\
\hline Vogue & http://www.vogue.es/ & 2001 \\
\hline Woman MF & http://www.woman.es/ & 2006 \\
\hline
\end{tabular}

Tabla 1: Páginas web de revistas femeninas en España y año de creación.

Fuente: Elaboración propia a partir de Ganzabal (2007a).

De lo anteriormente expuesto podemos advertir que Internet, además de una fuente inagotable de información, se ha convertido también en una herramienta muy potente para su difusión: por su inmediatez, porque admite cualquier contenido y temática y por la ausencia de censuras. Del mismo modo, la expansión de dispositivos electrónicos y tecnológicos como los ordenadores portátiles, smartphones o teléfonos inteligentes y tabletas ha posibilitado un acceso rápido e instantáneo a dichas plataformas (Sánchez, 2014). A esto se suman las redes sociales, Facebook, MySpace, Tuenti..., que se han convertido en uno de los elementos que más están influyendo en el nuevo panorama mediático (García, 2012).

\subsection{Las redes sociales, nuevo medio de comunicación}

En el nuevo escenario social del siglo XXI las redes adquieren gran relevancia, convirtiéndose en las grandes protagonistas de la sociedad digital (Caldevilla, 2010). Un protagonismo que va cada día en aumento, como reflejan las cifras que refieren la existencia de 3.484 millones de usuarios de redes sociales en todo el mundo, lo que supone un $43 \%$ de la población mundial (Hotsuite, 2019). 
De Twitter a Instagram: ¿Qué red social eligen las revistas de moda y belleza? | 187 ARTíCULOS DE INVESTIGACIÓN

Según Flores (2009), la propia Internet es la red social por excelencia, que ha posibilitado el desarrollo del resto de redes que se han convertido en un fenómeno de masas y plantean una nueva forma de comunicación. Para Caldevilla (2010, pp. 4547) “ha revolucionado nuestro concepto de relación social clásica y nuestra inversión en tiempo libre" y transformado totalmente el concepto tradicional de comunicación.

Y es en este contexto donde los tradicionales mass media empiezan a plantearse su supervivencia, que pasa en algunos casos y necesariamente por adaptarse a los cambios que ha traído Internet. Campos (2008) se refiere a las redes sociales como un nuevo medio de comunicación:

El nuevo fenómeno de las redes sociales suma audiencias millonarias, incrementa su publicidad, logra la personalización de los usuarios y rompe con algunas de las barreras de las viejas organizaciones mediáticas. Este nuevo medio de comunicación se cuela ya en las pantallas de millones de internautas como una de las principales fuentes de entretenimiento e información. (p. 277)

Algo en lo que también coincide Caldevilla (2010, p. 46) que se refiere a ellas no como un nuevo escenario sino como "un nuevo agente y un nuevo medio para tener en cuenta en el mapa de la comunicación y que despunta con gran fuerza generadora de opinión y tendencias". Por su parte, Noguera (2010, p. 178) incide en la necesidad de acercamiento de los medios a las redes sociales, aunque señala que "adentrarse con naturalidad y explotar al máximo las posibilidades periodísticas de las redes sociales es aún una tarea pendiente".

Entre los motivos que impulsan a los medios de comunicación a adaptarse a las redes sociales, Lara (2008) señala tres aspectos:

1. El perfil del público de medios está cambiando. El lector de medios tradicionales tiende a envejecer por lo que es necesaria una adaptación a las nuevas necesidades comunicativas e informativas de los jóvenes, que han nacido en la era digital y para quienes las redes sociales forman parte de su identidad digital.

2. Los usuarios de las redes crecen en número y en tiempo de permanencia. 


\section{ARTÍCULOS DE INVESTIGACIÓN}

3. Es una nueva forma de conectar con la sociedad, que goza de mayor confianza que los medios de comunicación tradicionales, que han perdido credibilidad en los últimos años. Además, permite la interacción con la audiencia y entre distintos usuarios, reforzando el concepto de comunidad.

El nuevo reto de los medios de comunicación es "captar nuevos públicos y convertir a sus audiencias en redes sociales" (Lara, 2008). Algo en lo que también incide Flores (2009, p. 75) que señala que "en los medios sociales las comunidades sustituyen a las audiencias".

¿Qué puede haber más interesante a nivel de audiencias para un medio que convertirse en un punto o lugar de encuentro o reunión de amigos o personas con intereses comunes? Así pues, los medios quieren ser redes sociales, aunque aún no han descubierto la fórmula para hacerlo, por lo que, de momento, sus primeros intentos se centran en tener presencia en aquellas redes con más seguidores o más significativas en función del perfil de su audiencia o del tipo de contenidos (texto, imagen, video...). Para Sánchez (2012), las redes sociales no son una opción en la comunicación de las empresas sino algo imprescindible.

Lógicamente, al igual que el resto de los medios, las revistas de moda y belleza no escapan a esta tendencia. "Así, tanto medios, instituciones, entidades y asociaciones, como empresas de todo tipo, incluidas las relacionadas con la industria de la moda, no han podido rechazar la oportunidad de estar presentes en la red, pudiendo ofrecer más alternativas y mejorar la experiencia, en este caso, del lector de las revistas de moda" (Font, 2015, p. 20).

\subsubsection{Las redes sociales de las revistas de moda y belleza: la importancia de la imagen}

En nuestra sociedad actual, la importancia de lo visual, de la imagen, es evidente. Incluso las redes sociales más "textuales", como Twitter, ofrecen hoy en día la posibilidad de ver fotos. Como afirma González (2014) las imágenes son gran parte del centro de nuestra vida y con ellas comunicamos mejor y más rápido. De hecho, cada vez más se está tendiendo hacia una red más visual. 
De Twitter a Instagram: ¿Qué red social eligen las revistas de moda y belleza? | 189 ARTÍCULOS DE INVESTIGACIÓN

De un tiempo a esta parte hemos visto como todas las redes sociales han ido cediendo cada vez más protagonismo a la parte visual del contenido web, desplegando cada vez imágenes más grandes y de mejor calidad. Hablamos de la imagen de portada de Facebook, de la posibilidad que ya ofrece Twitter de ver fotos sin salir de su canal (...) y de otros muchos indicios que nos muestran claramente el triunfo de lo visual por encima de lo textual. (González, 2014)

Las cualidades de la imagen a la hora de comunicar la han hecho triunfar sobre el texto en la Web 2.0, ya que permite explicar un mismo concepto de forma más sencilla y en menor tiempo que el texto (Mercedes y De la Morena, 2014).

Ante esta realidad no podemos perder de vista que en las ediciones online de las revistas femeninas la imagen prevalece sobre el texto, de modo que, tal como señala Armentia et al. (2011) se planifican más para ser vistas que leídas. Algo que no sorprende si tenemos en cuenta que, en las versiones impresas de estas cabeceras, la imagen predomina sobre el texto, especialmente la publicitaria, que supone un $27 \%$ de la paginación (Torres, 2007). Por lo que tampoco extraña que todas ellas tengan presencia en alguna de estas redes catalogadas como "visuales" (Font, 2015) o “basadas en la imagen" (Mercedes y De la Morena, 2014).

Entre las características que podemos destacar de estas redes sociales visuales frente a otro tipo de redes más textuales destaca el hecho de que el acceso a las mismas a través de dispositivos móviles es muy sencillo y que atrae a una audiencia más joven.

En estos últimos años y con la proliferación del uso de los smartphones y otros dispositivos móviles que poseen cámaras de fotos integradas, se ha fortalecido un tipo de red social que, por sus características de uso y facilidad para compartir el contenido que en ella se genera, ha calado en el usuario de la Web 2.0, un usuario que es cada vez más social y digitalmente activo; se trata de las redes sociales basadas en imágenes. (Mercedes y De la Morena, 2014, p. 155) 
Aunque las revistas de moda y belleza están presentes en las redes más populares y que cuentan con más seguidores -Facebook y Twitter-, tienen también una presencia significativa en redes visuales. Todas las revistas femeninas de moda y belleza, Cosmopolitan, Cuore Stilo, Divinity, Elle, Glamour, Harper's Bazaar, ¡Hola! Fashion, In Style, Marie Claire, Telva, Vogue y Woman MF, tienen presencia en Facebook, Twitter, Instagram, Pinterest y YouTube (a excepción ;Hola! Fashion y Divinity que no tienen presencia en la red de videos)

Instagram y Pinterest son las redes sociales basadas en imágenes que más popularidad han alcanzado en los últimos años (Mercedes y De la Morena, 2014), como se desprende del Estudio Anual Redes Sociales 2017 que las sitúan entre las diez primeras redes con más seguidores (en quinto y noveno lugar respectivamente) y además refleja una subida del 34\% con respecto al año anterior en el caso de Instagram y un $14 \%$ en Pinterest. Por otra parte, un $56 \%$ y un $39 \%$ de los usuarios de Instagram y Pinterest respectivamente han aumentado su frecuencia de visita a las mismas en el último año. En 2018, Instagram ocupa la cuarta posición y Pinterest la octava, por lo que ambas redes sociales han aumentado su uso en el último año (IAB Spain, 2018).

El mismo estudio, descubre por otra parte, que, en ambos casos, el perfil de su público está compuesto mayoritariamente por mujeres, existiendo una correspondencia con el sexo de las lectoras de las revistas femeninas. La importancia de estas redes queda también evidenciada por estudios como el de Mercedes (2015) que se refiere a una migración de los jóvenes de Facebook a Instagram.

Sin embargo, si tenemos en cuenta el hecho de que Pinterest e Instagram son redes sociales relativamente jóvenes, ambas nacen en 2010, no extraña que la literatura científica sobre el uso de las redes sociales basadas en imágenes en la prensa femenina de moda y belleza sea más bien escasa. De este modo, aunque no es objeto de la presente investigación hacer una incursión por la historia y recorrido de cada una de estas redes sociales, para lo que existen trabajos de obligada lectura como el de Font (2015), González (2014) o Mercedes y De la Morena (2014), entre otros, sí dedicaremos algunas líneas a reflexionar sobre la relación que dichas redes sociales puedan tener con las revistas de moda y belleza, objeto de la investigación que nos ocupa. 


\subsubsection{La relación de las redes visuales y las marcas de moda}

La relevancia de las redes sociales visuales para las cabeceras dirigidas a la mujer estriba en la importancia que tienen para las marcas. No podemos olvidar el carácter comercial de las revistas dirigidas a la mujer, en las que el propio contenido se nutre de las marcas, principalmente de moda y belleza. En esta línea, Mercedes y De la Morena (2014) destacan la relevancia que tanto Instagram como Pinterest tienen desde el punto de vista comercial y para los anunciantes y las firmas al permitirles, como señala De Salas (2009) mostrarse a su público de una manera menos institucional y mezclarse con él, permitiendo a las empresas hacer publicidad en formatos menos intrusivos y convertirse en una oportunidad de impacto publicitario gracias a la segmentación por interese, aficiones, etc.

Para Rodríguez (2015) las redes sociales humanizan las marcas comerciales y las conectan con la parte emocional de las personas. A través de estas redes se introducen en las escenas del día al día y se convierten en algo cotidiano.

La importancia de las redes para las marcas queda también evidenciada en el Estudio Anual Redes Sociales 2017 donde se recoge que el 83\% de los usuarios declara ser fan o seguir alguna marca a través de sus redes sociales. Además, más de la mitad declara haberse visto influenciado por ellas para su decisión de compra.

Estas cifras tienen también su reflejo en el aumento de la inversión publicitaria en redes sociales, de modo que los anunciantes están mostrando su interés por no perder esta oportunidad de negocio (De Salas, 2009).

Además y con respecto a Instagram, autoras como Font (2015) consideran que esta red se configura como fuerte competidora de las propias revistas femeninas, ya que son varias las instagramers reconocidas que se han convertido en portavoces de marcas de moda; hasta el punto de que se cuestionan si podrían sustituir a las tradicionales revistas femeninas, indicando que “las firmas (...) las han convertido en un intermediario que les permite acceder a los consumidores más fácilmente y a través de una vía más económica" (Font, 2015, p. 3). Así pues, se ponen en contacto con las influencers de Instagram para enviarles sus prendas, conscientes de que 


\section{ARTÍCULOS DE INVESTIGACIÓN}

si se fotografían con la ropa o complementos de la marca y suben estas imágenes a la red social, miles de followers las imitarán en sus estilismos.

Aspecto en el que también coincide Basoa (2014, p.18), para quien la relación entre moda e Internet ha generado nuevas profesiones como los bloggers que "son grandes influyentes en las decisiones de compra y en la creación de tendencias".

Las redes sociales se convierten en grandes aliadas de la industria de la moda porque permiten que la moda, las tendencias, lleguen a todo el mundo antes; de modo que "las imágenes, los artículos y los estilos se crean y se dispersan por el mundo con mucha más rapidez" (Martínez, 2006, p. 188).

Nacen webs corporativas, revistas digitales, blogs y bloggers, que llegan para "renovar la industria, la comunicación y los hábitos de consumo de la moda" (Font, 2015 , p. 5). Además, Font (2015) reconoce la importancia que la propia red tiene para las revistas femeninas, señalando que, aparte de ser empleadas como soporte publicitario por las marcas, las propias publicaciones en su formato digital las utilizan para "compartir" sus contenidos; de forma que las redes sociales se han convertido en escaparates "a través de los cuales los usuarios expresan opiniones, sentimientos y en cierta manera, su propia personalidad" (Font, 2015, p. 31).

Con relación a Pinterest, para González (2014) se trata de "la red social visual por excelencia, la que alcanzó más rápido que ninguna otra los 10 millones de usuarios". Mercedes y De la Morena (2014) la señalan como una de las redes más atractiva para el público femenino y de gran importancia antes de tomar una decisión de compra, indicando que son muchas las marcas en todo el mundo que tienen perfil en dicha red.

Por último, con respecto a YouTube, Amaya y Rojas (2016) indican que se ha convertido en una red muy importante para la difusión de la moda, con el auge de youtubers que suben contenido a la plataforma con consejos de moda que, en muchas ocasiones, incide en la decisión de compra de aquellos que los siguen. 
En función a los aspectos comentados anteriormente se plantea la hipótesis que considera que las revistas femeninas tienen más repercusión en aquellas redes sociales que dan más protagonismo a la imagen, como Instagram, Pinterest o YouTube, ya que la temática de estas publicaciones se centra fundamentalmente en contenidos de moda y belleza, aspectos con un alto componente visual. De este modo, entendemos que es en dichas redes sociales donde estas publicaciones se desenvuelven con más comodidad y naturalidad, al ser cabeceras que tanto en su versión impresa como digital giran en torno a contenido eminentemente comercial, donde las marcas son las grandes protagonistas y donde las fotografías e imágenes tienen un papel fundamental, no solo en las páginas publicitarias sino incluso en el contenido de las mimas.

\section{Metodología}

Mediante la técnica del análisis de contenido se estudiarán las redes sociales más empleadas por las revistas femeninas de moda y belleza. La investigación abarca un periodo temporal de doce meses, comprendido entre el 1 de julio de 2018 y el 30 de junio de 2019.

Para proceder a la selección de la muestra se ha tenido en cuenta cuales son las revistas más representativas atendiendo a los datos facilitados por el informe ARI $360^{\circ}$, que mide la audiencia en múltiples plataformas y formatos, incluyendo ediciones en papel, digitales, webs, video y redes sociales. Como el periodo de análisis comprende los seis últimos meses de 2018 y el primer semestre de 2019 y las redes sociales analizadas son Facebook, Twitter, Instagram, Pinterest y YouTube, solo se han considerado las cifras referidas a dichas redes y con datos acumulados a junio de 2019.

\begin{tabular}{|l|c|}
\hline \multicolumn{1}{|c|}{ Cabecera } & Contactos junio 2019 \\
\hline Cosmopolitan & 2.843 .161 \\
\hline Cuore Stilo & 633.356 \\
\hline Divinity & 17212 \\
\hline
\end{tabular}


194 | Dra. Ruth Gómez de Travesedo Rojas y Dra. Marta Gil Ramírez ARTÍCULOS DE INVESTIGACIÓN

\begin{tabular}{|l|c|}
\hline \multicolumn{1}{|c|}{ Cabecera } & Contactos junio 2019 \\
\hline Elle & 4.107 .375 \\
\hline Glamour & 2.444 .985 \\
\hline Harper's Bazaar & 945.059 \\
\hline iHola! Fashion & 2.145 .025 \\
\hline In Style & 219.175 \\
\hline Marie Claire & 1.742 .697 \\
\hline Telva & 2.249 .814 \\
\hline Vogue & 7.071 .356 \\
\hline Woman MF & 1.001 .882 \\
\hline
\end{tabular}

Tabla 2: Audiencia de revistas femeninas en RRSS.

Fuente: Elaboración propia a partir de ARI $360^{\circ}$.

Las revistas con más contactos son Vogue, Elle, Cosmopolitan y Glamour, en este orden; que en todos los casos superan los dos millones. Se han seleccionado, por lo tanto, estas cuatro cabeceras como las más representativas en cuanto a audiencia en las cinco redes sociales que queremos analizar.

Para llevar a cabo el análisis de cada una de las redes nos centraremos en aspectos formales y de interacción mediante una ficha de análisis de contenido y con la ayuda de la herramienta Fanpage Karma, que ofrece métricas sobre las diferentes redes sociales.

Las variables formales analizadas son número de seguidores y de publicaciones; las variables de interacción comprenden total de interacciones, reacciones, compartidos, etc. y compromiso. Los criterios analizados en cada una de las redes han sido el nivel de visibilidad y exposición, así como el nivel de interacción e involucración de sus seguidores, a través de los like o me gusta, elementos compartidos, guardados, comentarios, etc. Así podremos conocer:

- El tamaño de la audiencia o comunidad (fans, followers, seguidores, contactos, suscriptores...) de cada una de las redes y su crecimiento. 
De Twitter a Instagram: ¿Qué red social eligen las revistas de moda y belleza? | 195 ARTÍCULOS DE INVESTIGACIÓN

- Número de publicaciones, tuits, pins, videos... e interacciones a través de comentarios, contenidos compartidos, me gusta, etc.

- El compromiso o fidelidad, que mide el grado de involucración de la audiencia.

Advertir que no pretendemos un análisis comparativo entre las distintas cabeceras por lo que estudiaremos de forma conjunta el uso que hacen las revistas femeninas de las redes, con el objeto de comprobar si se verifica nuestra hipótesis inicial que afirma que dichas publicaciones centran sus esfuerzos en redes visuales; aunque en algunos casos será obligada una referencia a los resultados individuales de cada una de ellas para una mejor interpretación y comprensión de los datos.

\section{Análisis y resultados}

El análisis se enmarca en el periodo de julio de 2018 a junio de 2019, pero, al no facilitar la herramienta utilizada el dato de seguidores de Pinterest en Elle para este periodo, hemos tomado los datos del informe ARI $360^{\circ}$, que reflejan el número de seguidores en todas las redes sociales hasta la fecha en la que se cierra el análisis. Se trata de un dato acumulativo, que tiene en cuenta altas y bajas, lo que nos permite comprobar cuál es a fecha de cierre del periodo de análisis la situación de cada una de las revistas en las distintas redes en cuanto al número de seguidores.

Facebook y Twitter son las redes que cuentan con un mayor número de seguidores, que superan los seis millones en el cómputo total de las cuatro cabeceras (6.720.188 y 6.179.486 respectivamente); seguida de Instagram, con más de dos millones y medio de seguidores (2.650.789) y a mayor distancia YouTube (504.354 suscriptores) y Pinterest (412.060 seguidores). De este modo, son las redes textuales las que tienen mayor número de seguidores, frente a las visuales que en general son menos seguidas por la audiencia de estas revistas.

Vogue y Cosmopolitan son las que cuentan con más seguidores en Twitter, mientras que Elle y Glamour tienen más usuarios a través de Facebook. La cifra más alta de seguidores en Instagram corresponde a Vogue, con algo más de un millón trescientos mil. También es la decana de las revistas de moda la que cuenta con el 
mayor número de usuarios en Pinterest (290.111) y YouTube (284.959), siendo la que destaca en todas las redes analizadas.

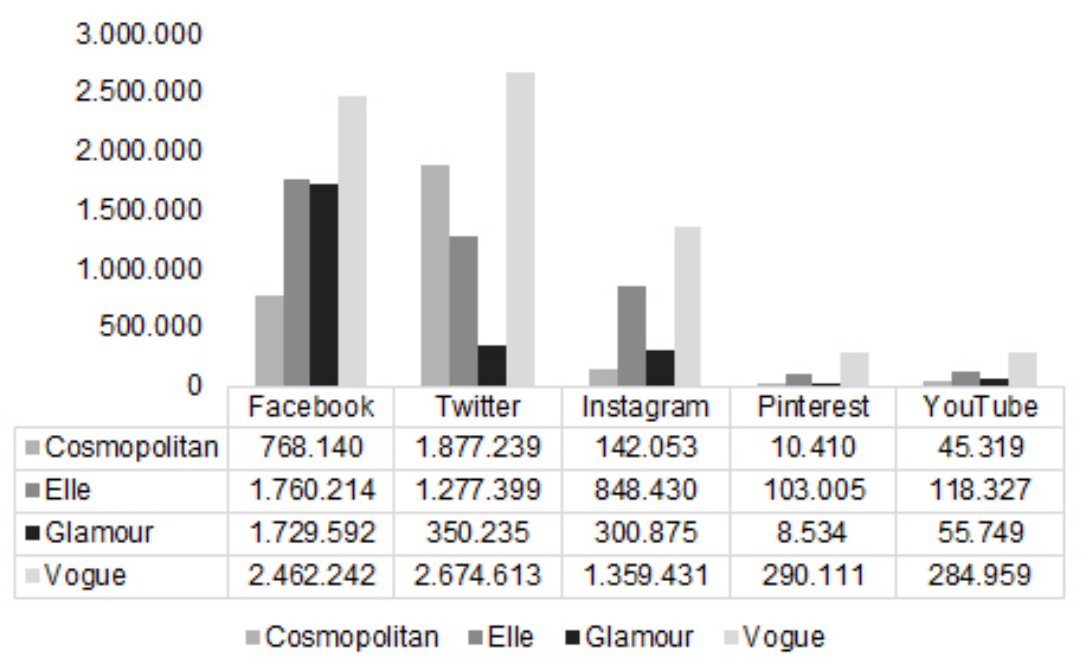

Gráfico 1: Número de seguidores. Fuente: Elaboración propia.

Facebook y Twitter no son solo las redes que tienen más seguidores sino también en las que más han publicado las revistas en el periodo analizado, con un total de 44.831 y 45.491 publicaciones respectivamente, que se traduce en una media de 11.208 y 11.373. La actividad en Instagram es menor, con una media de 636 publicaciones en todo el periodo $\mathrm{y}$, en último lugar, YouTube con solo 249 publicaciones.

Glamour es la más activa en Facebook y Twitter, aunque descuida las redes visuales. Sin embargo, destaca positivamente el número de publicaciones en Pinterest por parte de Vogue (2.344 pines en doce meses), frente a los escasos 364 de Elle, los 272 de Cosmopolitan o los 115 de Glamour. Elle es, detrás de Vogue, la segunda revista más activa de las cuatro analizadas en Instagram, con 850 publicaciones en todo el periodo.

Por otra parte, debemos hacer una lectura negativa del hecho de que, aunque la página de Pinterest de Elle tenga más de 103.005 seguidores, siendo la segunda de las cabeceras con más usuarios en dicha red social, tan solo haya publicado 364 pines. 
En resumen, Vogue es la revista más activa, que más publica en Pinterest e Instagram, y Glamour en Facebook y Twitter, mientras que Elle es la que destaca en la plataforma de videos YouTube.

\begin{tabular}{|l|c|c|c|c|c|}
\hline \multicolumn{1}{|c|}{ Cabecera } & Facebook & Twitter & Instagram & Pinterest & YouTube \\
\hline Cosmopolitan & 9.647 & 9.587 & 318 & 272 & 154 \\
\hline Elle & 10.552 & 11.634 & 850 & 364 & 414 \\
\hline Glamour & 14.728 & 12.615 & 367 & 115 & 309 \\
\hline Vogue & 9.904 & 11.655 & 1.009 & 2.344 & 118 \\
\hline Total & 44.831 & 45.491 & 2544 & 3095 & 995 \\
\hline
\end{tabular}

Tabla 3: Número de publicaciones.

Fuente: Elaboración propia.

Si analizamos la variable del número de publicaciones por día ${ }^{4}$ podemos apreciar de nuevo como las revistas son más activas en redes textuales, con cifras que oscilan entre las 40 y las 26 publicaciones/día en el caso de Facebook, y entre las 34 y 26 en Twitter. En términos generales el nivel de actividad de las revistas es de una media de 30 publicaciones/día en redes textuales. Sin embargo, para Pinterest es de apenas 2,12 publicaciones/día y similar es el comportamiento en Instagram, donde la actividad es aún menor (1,74 publicaciones/día).

La responsable de que Pinterest se sitúe por delante de Instagram es Vogue, la revista más activa en dicha red (6,42 publicaciones/día). También lo es en Instagram (2,76 publicaciones/día). Sin embargo, resulta curioso que esta revista cuente con más seguidores en esta última red aunque dedique sus mayores esfuerzos a Pinterest. 


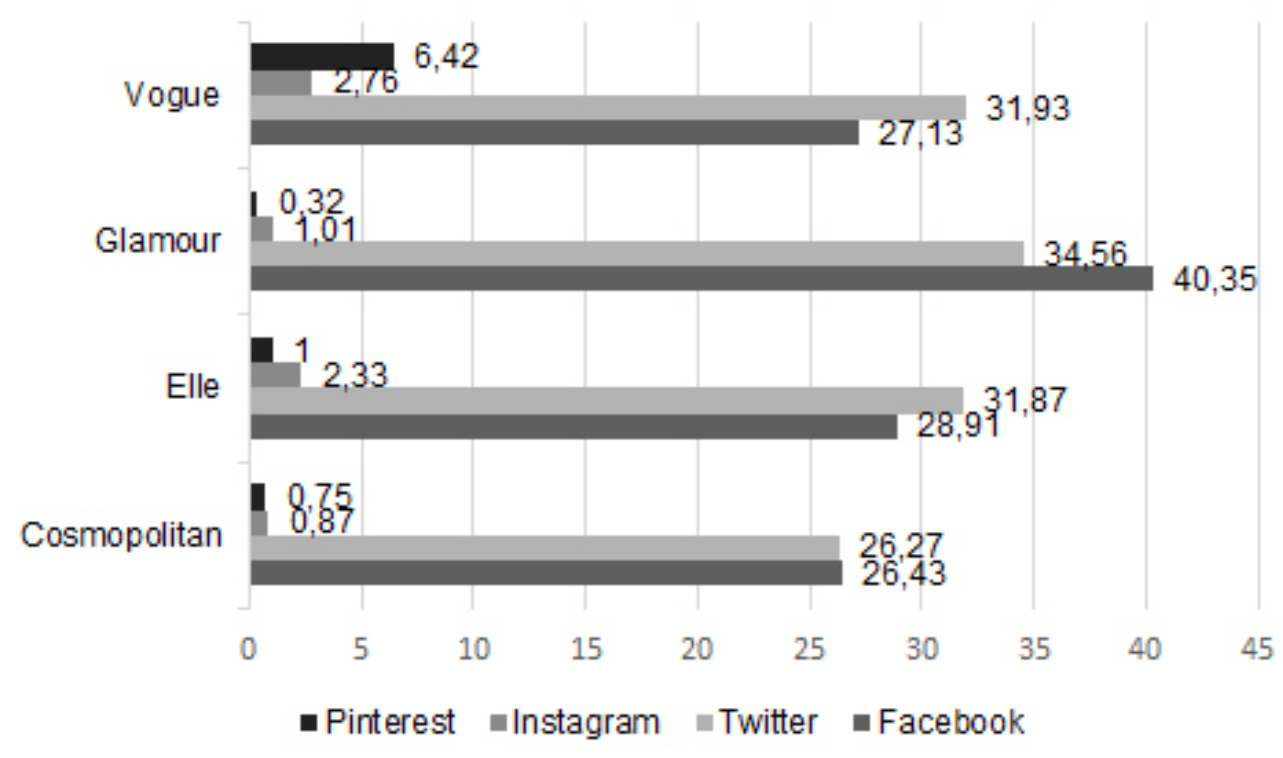

Gráfico 2: Publicaciones/día. Fuente: Elaboración propia.

Con respecto a Facebook la herramienta empleada para la recopilación de datos nos ofrece información sobre el número de videos, imágenes, enlaces y estados publicados, así como el nivel de interacción con cada uno de ellos. Analizando de forma individualizada el número de imágenes y videos que se publican podemos apreciar que suponen en términos globales un $15,68 \%$ de las publicaciones en dicha red, así como advertir que se suben más imágenes que videos (10,63\% fotografías y 5,05\% videos).

Glamour es la cabecera que utiliza más imágenes (2.258), mientras que Vogue sube el mayor número de videos (903). Aunque este tipo de contenidos son minoritarios con respecto al resto, son a los que más reaccionan los usuarios, es decir, reciben más me gusta, se comparten y se comentan más.

Si calculamos la relación entre los tipos de publicaciones y el número de interacciones recibidas podemos apreciar como los contenidos con más reacciones, comentarios y compartidos son principalmente videos (629,90 interacciones/publicación) y fotografías (202,17 interacciones/publicación). 
De Twitter a Instagram: ¿̨Qué red social eligen las revistas de moda y belleza? | 199 ARTíCULOS DE INVESTIGACIÓN

\begin{tabular}{|l|c|c|c|}
\hline Cabecera & Total interacciones & Total publicaciones & $\begin{array}{c}\text { Media interacciones/ } \\
\text { publicación }\end{array}$ \\
\hline Videos & 1.419 .931 & 2.265 & 626,90 \\
\hline Fotos & 958.384 & 4.764 & 210,17 \\
\hline Estados & 4161 & 110 & 37,83 \\
\hline Link/enlaces & 3.622 .513 & 37.692 & 96,11 \\
\hline
\end{tabular}

Tabla 4: Interacciones en Facebook por tipo de publicación.

Fuente: Elaboración propia.

Tras analizar seguidores y contenidos nos interesa conocer las interacciones de los usuarios en cada una de las redes, que es mayor en Instagram y Facebook. El total de interacciones en Instagram es de 8.103.883, 6.505.484 en Facebook, 814.167 en Twitter, 292.622 en YouTube y, por último, 35.507 en Pinterest (32.831 de Vogue). Sin embargo, se trata de valores absolutos por lo que es interesante observar otro aspecto como es el compromiso ${ }^{5}$ de los usuarios con la página.

Es en este punto donde llama la atención los porcentajes tan bajos, que en ningún caso llegan al 2\%, siendo el más alto el de la revista Elle en Instagram, con un 1,21\%; y con una media entre todas las revistas del 0,24\% para Facebook y $0,04 \%$ en Twitter. Sin embargo, el porcentaje de compromiso es mayor en la red visual Instagram $(0,83 \%)$, aunque continúa siendo escaso en Pinterest $(0,06 \%)$. La lectura que podemos hacer de estos datos es que los usuarios más comprometidos son los de Instagram, por encima incluso de los que siguen las revistas a través de Facebook.

Por último, la variable de crecimiento nos permite apreciar como la red que más ha crecido en el periodo analizado es YouTube, seguida de Instagram y Pinterest; todas ellas redes visuales. Sin embargo, Elle ha registrado un decremento del 100\% en Pinterest, aunque es la segunda cabecera en número de seguidores y publicaciones en dicha red. A pesar de ello el crecimiento del 134\% experimentado por Vogue mantienen las cifras de Pinterest por delante de las redes textuales como Facebook y Twitter, que han registrado descensos en casi todas las revistas, en algunos casos de casi un 3\%, siendo Vogue la única cabecera que ha crecido en Facebook. 
200 | Dra. Ruth Gómez de Travesedo Rojas y Dra. Marta Gil Ramírez

ARTÍCULOS DE INVESTIGACIÓN

\begin{tabular}{|l|c|c|c|c|c|}
\hline \multicolumn{1}{|c|}{ Cabecera } & Facebook & Twitter & Instagram & Pinterest & YouTube \\
\hline Cosmopolitan & $-0,60 \%$ & $-2,78 \%$ & $30,00 \%$ & $0,95 \%$ & $23,77 \%$ \\
\hline Elle & $-0,47 \%$ & $-2,18 \%$ & $6,4 \% * 6$ & $-100,00 \%$ & $17,53 \%$ \\
\hline Glamour & $-0,93 \%$ & $-0,86 \%$ & $7,40 \%$ & $9,80 \%$ & $27,33 \%$ \\
\hline Vogue & $1,20 \%$ & $-2,55 \%$ & $17,00 \%$ & $134,47 \%$ & $29,51 \%$ \\
\hline Media & $-0,20 \%$ & $-2,09 \%$ & $13,60 \%$ & $11,31 \%$ & $24,54 \%$ \\
\hline
\end{tabular}

Tabla 5: Crecimiento de las RRSS.

Fuente: Elaboración propia.

\section{Discusión}

Las redes con más seguidores y más publicaciones son redes textuales -Facebook y Twitter-, sin embargo, el nivel de compromiso y crecimiento es mayor en redes visuales. Instagram en lo que respecta a compromiso y YouTube en crecimiento, algo que no sorprende teniendo en cuenta la gran importancia que actualmente tiene dicha red. De ello podemos deducir que la red de videos se configura como un soporte que, aunque actualmente no parece contar con la suficiente atención de las revistas femeninas, no deberían pasar por alto, entre otros aspectos por el crecimiento que está experimentando en los últimos años y el que parece va a experimentar en un futuro.

Con respecto a la interacción de las publicaciones en todos los casos es muy escasa, pero, resulta curioso que, aunque las revistas femeninas dediquen sus esfuerzos a redes textuales, sea Instagram la red que tiene un mayor compromiso por parte de los usuarios. Además, Vogue es bastante activa en otra red visual como es Pinterest. Estos datos reflejan como estas cabeceras se han percatado del poder de la imagen y de las posibilidades de estas redes sociales más jóvenes y que se adaptan mejor a sus temáticas y contenidos.

Podemos concluir que, aunque las revistas femeninas de alta gama en soporte papel se centran fundamentalmente en contenidos de moda y belleza y conceden gran importancia a la imagen sobre el texto -algo que también se refleja en sus ediciones online- las redes sociales con más alcance no son, de momento, redes visuales, como 
De Twitter a Instagram: ¿̨Qué red social eligen las revistas de moda y belleza? | 201 ARTÍCULOS DE INVESTIGACIÓN

planteábamos en nuestra hipótesis inicial, sino las redes que más usuarios tienen a nivel no solo nacional sino mundial: Facebook y Twitter. Sin embargo, sí advertimos que, incluso en estas redes más textuales, la importancia de la imagen es fundamental para estas cabeceras con contenidos que aparecen acompañados de imágenes y videos y que además son los que provocan más reacciones en sus seguidores.

Tampoco debemos perder de vista a la hora de interpretar nuestro análisis la perspectiva de las distintas edades de las redes sociales. Mientras Facebook o Twitter son redes con más de diez años, Pinterest e Instagram son más jóvenes. Futuras líneas de investigación podrían ir encaminadas a analizar si el compromiso y nivel de actividad de las revistas femeninas en este tipo de redes visuales avanza positivamente con el tiempo y se produce un transvase de redes textuales a visuales, algo que parece estar ya empezando a suceder, a tenor de los datos que reflejan el porcentaje de decrecimiento de las redes textuales.

Quizá no haga falta esperar mucho tiempo más para apreciar una tendencia que impulse a estas cabeceras a centrarse más en redes visuales, sobre todo si atendemos al nivel de interacción de los usuarios o seguidores, que es mayor en este tipo de redes, aunque el nivel de actividad de las cabeceras sea escaso, lo que refleja las preferencias del público más activo y con más nivel de compromiso por redes como YouTube, Instagram o Pinterest.

Facebook y Twitter son los reyes de las redes sociales también en el caso de las revistas de moda y belleza, sin embargo, el resto de las redes escalan cada día más posiciones, sobre todo aquellas en las que la imagen, ya sea fija o en movimiento, es un elemento principal, especialmente en una sociedad donde como ya hemos advertido anteriormente "una imagen vale más que mil palabras".

\section{Referencias}

Albertos, J. L. M. (1997). El ocaso del periodismo. Barcelona, España: CIMS Amaya Lavalle, G., y Rojas Atarama, T. A. (2016). YouTube como herramienta de marketing estratégico para la moda: Análisis del canal oficial What the chic en el 2015. adComunica, (12), pp. 91-108. doi: 10.6035/2174-0992.2016.12.6 


\section{ARTÍCULOS DE INVESTIGACIÓN}

Armentia Vizuete, J. I., Ganzabal Learreta, M. y Marín Murillo, M. F. (2011). La perspectiva de género en las ediciones digitales de las revistas femeninas y masculinas españolas. En Comunicación y desarrollo en la era digital. Congreso $A E$-IC 3, 4 y 5 de febrero de 2010. Recuperado de http://bit.ly/2IVW2re ARI (2019). Informe ARI 360 . Informe de audiencia de revistas. Recuperado de https://bit.ly/2Lzp5R8

Ayestarán Crespo, R. (2011). Revistas femeninas ante la transición digital: su expansión de marca como base del modelo de financiación de sus grupos editoriales en España (tesis doctoral). Universidad Complutense de Madrid, Madrid. Recuperado de http://bit.ly/2GZEQ1J

Basoa Portos, A.M. (2014). La moda en la red: la web 2.0 (trabajo fin de Grado). Universidad da Coruña, La Coruña. Recuperado de http://bit.ly/2JcWDnB

Caldevilla Domínguez, D. (2010). Las Redes Sociales. Tipología, uso y consumo de las redes 2.0 en la sociedad digital actual. Documentación de las Ciencias de la Información, 33, pp. 45-68. Recuperado de http://bit.ly/2GWZ0JQ

Campos Freire, F. (2008). Las redes sociales trastocan los modelos de los medios de comunicación tradicionales. Revista Latina de comunicación social, 11(63), pp. 277-286. Recuperado de https://bit.ly/2PlFdH1

Canga Larequi, J. (2001). Periodismo e Internet: nuevo medio, vieja profesión. Estudios sobre el mensaje periodístico, 2001(7), pp. 33-48. Recuperado de http://bit.ly/2PGF4gZ

Castells, M. (2000). Internet y la sociedad red. En Conferencia de Presentación del Programa de Doctorado sobre la Sociedad de la Información y el Conocimiento. Universitat Oberta de Catalunya, Vol. 7, pp. 1-13. Recuperado de http://bit.ly/2DHMCLO

De Salas Nestares, M I. (2010). La publicidad en las redes sociales: de lo invasivo a lo consentido. Icono14, 8(1), 5. pp. 75-84. doi: 10.7195/ri14.v8i1.281

Flores Vivar, J. M. (2009). Nuevos modelos de comunicación, perfiles y tendencias en las redes sociales. Comunicar, 17(33), pp.73-81. doi: 10.3916/c33-2009-02-007

Font Marsal, M. (2015). Comunicar la moda: De las revistas femeninas al fenómeno Instagram (trabajo fin de grado). Facultad de Ciencias de la Comunicación. Universidad Autónoma de Barcelona, Barcelona. Recuperado de http://bit.ly/2WknDW3

Gabelas Barroso, J. A. y Marta Lazo, C. (2011). Adolescentes en la cultura digital. En Martínez R., E. y Marta L., C. (Coords.), Jóvenes Interactivos. Nuevos modos de comunicarse, pp. 03- 15. La Coruña, España: Netbiblio. 
De Twitter a Instagram: ¿̨Qué red social eligen las revistas de moda y belleza? | 203 ARTÍCULOS DE INVESTIGACIÓN

Ganzabal Learreta, M. (2006). Nacimiento, remodelación y crisis de la prensa femenina contemporánea en España. Revista latina de comunicación social, 9(61). Recuperado de http://bit.ly/2Jbc5k6

- (2007a). La inevitable presencia de las revistas femeninas de alta gama en la red. En Verón Lassan, J.J. y Sabés Turmo, F. (Coords.), Presente y futuro de la comunicación digital (pp. 69-80). Huesca, España: Asociación de Prensa de Aragón.

- (2007b). La popularización versus la democratización de las revistas femeninas de alta gama. Question. 1 (16). Recuperado de http://bit.ly/2LswuDU

- (2008). Hacia la miniaturización de la prensa femenina. El caso Glamour. Ámbitos, (17), pp. 91-105. Recuperado de https://bit.ly/2RvY7gW

García, M. A. (2012). Redes sociales, contenidos publicitarios y dispositivos móviles. Revista Icono14. Revista científica de Comunicación y Tecnologías emergentes, 7(1), pp. 162-173. doi: 10.7195/ri14.v7i1.339

González Macías, M. A. (2014). Pinterest. La red social visual y creativa. Barcelona, España: Editorial UOC.

Hootsuite (2019). Digital 2019. Recuperado de http://bit.ly/2GYn2Ek

IAB Spain (2017). Estudio Anual Redes Sociales 2017. Recuperado de http://bit. ly/2DJbbI1

IAB Spain (2017). Estudio Anual Redes Sociales 2018. Recuperado de http://bit. ly/2vHz3rn

Lara, T. (2008). La nueva esfera pública. Los medios de comunicación como redes sociales. Telos, 76, pp. 128-131. Recuperado de http://bit.ly/2vxhhXw

Martínez Barreiro, A. (2006). La difusión de la moda en la era de la globalización. Papers: revista de sociología, (81), pp. 187-204. doi: 10.5565/rev/papers.2038 Mercedes, G. V. M. (2015). Migración de los jóvenes españoles en redes sociales, de Tuenti a Facebook y de Facebook a Instagram. La segunda migración. Icono14, 13(2), pp. 48-72. doi: 10.7195/ri14.v13i2.821

Mercedes, G.V.M. y de la Morena Taboada, M. (2014). Redes sociales basadas en imágenes como herramienta de comunicación museística. Museos y centros de arte Moderno y Contemporáneo de España en Pinterest e Instagram. adComunica, (8), pp. 139-168. doi: 10.6035.2174-0992.2014.8.9

Noguera Vivo, J. M. (2010). Redes sociales como paradigma periodístico. Medios españoles en Facebook. Revista latina de comunicación social, (65), pp. 176186. doi: 10.4185/RLCS-65-2010-891-176-186 


\section{ARTÍCULOS DE INVESTIGACIÓN}

Rodríguez Díez, P. (2015). Il Tempietto de Segovia en las redes sociales: Inicio, desarrollo y consolidación de una marca en la web 2.0 (trabajo fin de grado). Facultad de Ciencias Sociales, Jurídicas y de la Comunicación, Segovia. Recuperado de http://bit.ly/2GXSame

Sánchez, E. (2012). El social media en la estrategia de comunicación. adComunica, (3), pp. 221-222. doi: 10.6035/2174-0992.2012.3.16

Sánchez Martínez, R. (2014). El fenómeno de los blogs de moda: un análisis de las nuevas técnicas de marketing vinculadas a las redes sociales (trabajo fin de máster). Universidad Pública de Navarra, Navarra. Recuperado de http://bit.ly/2UVfV2U

Torres, R. (2007). Revistas de moda y belleza: el contenido al servicio de la forma bella. Ámbitos, (16), pp. 213-225. Recuperado de https://bit.ly/2RtT7tl

\section{Notas}

[1] Telva es la única revista nacional de la época que logra sobrevivir a la "invasión" de las editoras internacionales y continúa editándose actualmente desde 1963.

[2] El Marco General de los Medios en España 2019, con datos del 2018, sitúa a Vogue, Elle y Cosmopolitan entre las diez revistas mensuales más leídas en nuestro país, con cifras de audiencia que en el caso de Vogue se acerca a las de diarios de información general como El Mundo.

[3] RFAG: Revista femenina de alta gama.

[4] El dato de publicaciones/día no se encuentra disponible para YouTube.

[5] El dato de compromiso no se encuentra disponible para YouTube.

[6] El dato de crecimiento para Elle en Instagram no está disponible para el periodo indicado. Se ha tomado como referencia el del año 2018, de enero a diciembre.

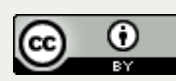

Este obra está bajo una licencia de Creative Commons Reconocimiento 4.0 Internacional. 